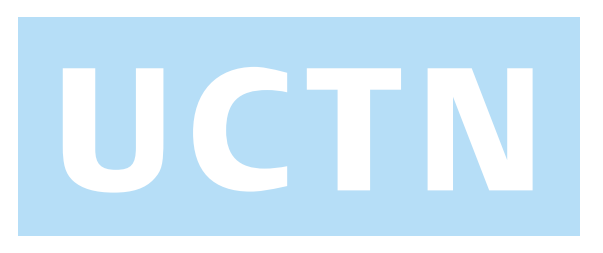

\title{
Delayed Massive Hemobilia After Biliary Stenting
}
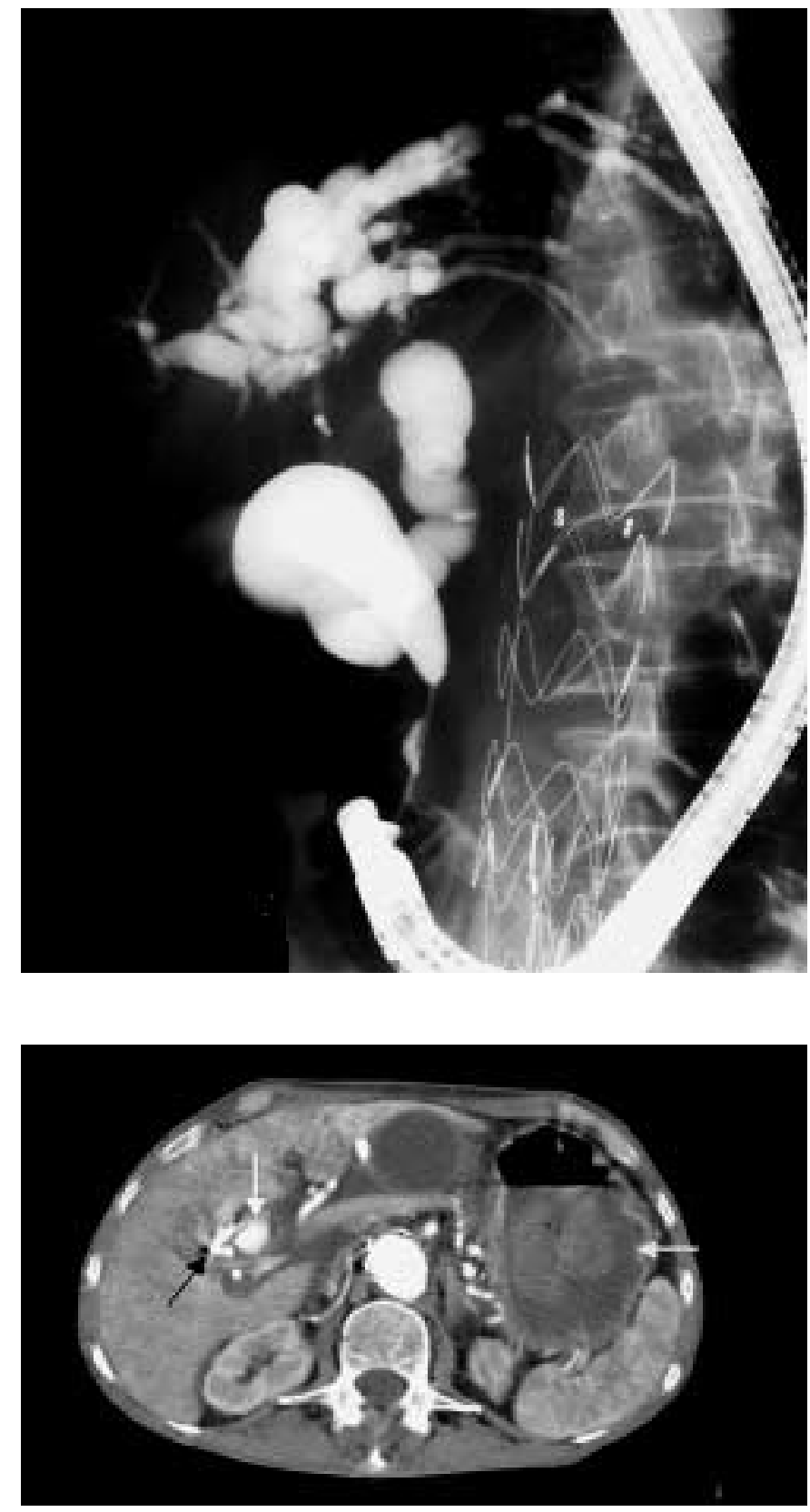

Figure 2 Computed tomography (CT) scan during the arterial phase demonstrating a hyperdense spot (white arrow) adjacent to a feeding artery, suggestive of an active arterial bleed close to the proximal tip of the biliary endoprosthesis (black arrow). Note the heterogenic filling of the gastric remnant (grey arrow), which was known to be due to massive amounts of fresh blood.

A 75-year-old man presented with jaundice. His medical history included Billroth II gastrectomy, long-standing alcohol abuse, and aortic stent insertion. A com-
Figure 1 Endoscopic retrograde cholangiopancreatography (ERCP) showed a dilated intrahepatic bile duct system, and a dilated and tortuous common bile duct with distal narrowing, possibly due to extrinsic compression by pancreatic pseudocysts. mon bile duct $(\mathrm{CBD})$. Endoscopic retrograde cholangiopancreatography (ERCP) revealed dilatation of the intrahepatic ducts and a dilated and tortuous CBD with distal narrowing (Figure 1). A 15$\mathrm{cm}, 10$-Fr biliary endoprosthesis was inserted without sphincterotomy, and there was subsequent clinical improvement.

The patient was readmitted 3 weeks later with cholangitis. ERCP was unsuccessful because of compression on the afferent limb by the pancreatic pesudocysts. Shortly afterwards the patient developed shock and signs suggestive of a gastrointestinal bleed. At gastroscopy, copious fresh blood was seen in the gastric remnant, but no bleeding focus was found. CT scan demonstrated active arterial bleeding from a main hepatic artery (Figure 2).

Laparotomy revealed that the endobiliary prosthesis had eroded into a major branch of the right hepatic artery with significant hemobilia. Choledochotomy was performed with extraction of the prosthesis and ligation of the spurting vessel with subsequent choledochoduodenostomy, cystojejunostomy of the pancreatic pseudocyst and Roux-en-Y reconstruction. The patient had a rapid and uneventful postoperative recovery.

Major hemobilia as a complication of nontraumatic ERCP is rare; it has been described in one case report [1], but has not been reported in large prospective series $[2,3]$ or in recent reviews dealing with therapeutic biliary endoscopy and its risk $[4,5]$. It is likely that the long endoprosthesis, chosen in this case in order to unfold the elongated $\mathrm{CBD}$, became wedged into the parenchyma of the right hepatic lobe causing forceful erosion of a major artery. A shorter endoprosthesis might have been a better choice, since drainage of the distal biliary stenosis would have been accomplished without harming the hepatic vasculature. This report describes a rare complication of ERCP and highlights a potential risk in using a long endoprosthesis. 
F. Wolters', B. Ryan'1, R. Beets-Tan²,

\section{Dejong ${ }^{3}$}

${ }^{1}$ Department of Gastroenterology and Hepatology, Academic Hospital Maastricht, Maastricht, The Netherlands

${ }^{2}$ Department of Radiology, Academic Hospital Maastricht, Maastricht, The Netherlands

${ }^{3}$ Department of Surgery, Academic Hospital Maastricht, Maastricht, The Netherlands

\section{References}

${ }^{1}$ Gholson CF, Williams C, Patterson CR. Bloody drainage following endoscopic retrograde pancreatography as a presentation of a pseudoaneurysm-containing pseudocyst. Gastrointest Endosc 1989; 35: 111
${ }^{2}$ Loperfido S, Angelini G, Benedetti Get al. Major early complications from diagnostic and therapeutic ERCP: a prospective multicenter study. Gastrointest Endosc 1998; 48: 1 - 10

${ }^{3}$ Masci E, Toti G, Mariani Aet al. Complications of diagnostic and therapeutic ERCP: a prospective multicenter study. Am J Gastroenterol 2001; 96: 417-423

${ }^{4}$ Shah SK, Mutigagni M, Costamagna G. Therapeutic biliary endoscopy. Endoscopy 2002; 34: 43-53

${ }^{5}$ François E, Devière J. Endoscopic retrograde cholangiopancreatography. Endoscopy 2002; 34: 882-887
Corresponding Author

\section{F. Wolters, M.D.}

Department of Gastroenterology and Hepatology

PO Box 5800

6202 AZ Maastricht

The Netherlands

Fax: $\quad+31-43-3875006$

E-mail: fwo@sint.azm.nl 